\title{
WHY ARE NEW PATIENTS COMING TO THE EYE CLINIC? AN ANALYSIS OF THE RELATIVE FREQUENCIES OF OPHTHALMIC DISEASE AMONGST NEW PATIENTS ATTENDING HOSPITAL EYE CLINICS IN TWO SEPARATE LOCATIONS
}

\author{
CHARLES CLAOUÉ, ALEX FOSS, ROD DANIEL and BOB COOLING \\ London
}

\begin{abstract}
SUMMARY
We have analysed 64417 patient-attendances by 56409 patients to a dedicated ophthalmic new patient service to assess the demographic and epidemiological parameters of this population. Forty-three point five per cent were male and $56.5 \%$ female. Nine per cent of patients were under 16 years of age while $27.5 \%$ were over 70 years. Comparison of patients attending an outreach new patient clinic with that at the main hospital showed that a higher proportion of patients under 16 years were seen at the outreach clinic $(p<0.001)$, whereas the main clinic saw a higher proportion of patients in the 16-69 year age group $(p<0.001)$.
\end{abstract}

In 1990, a fundamentally new strategy for delivering care to patients with ophthalmic disorders was introduced at Moorfields Eye Hospital. Briefly, all new patient-episodes were selectively channelled to a dedicated new patient clinic that we chose to call the 'Primary Care Clinic' or PCC. The aim of this clinic is to provide a one-stop diagnostic service, i.e. all necessary diagnostic services such as optometry, refraction and visual field analysis are available at a patient's first visit. At the end of this visit, the ophthalmologist is usually able to make a definitive diagnosis and the patient may be counselled and discharged, treated and discharged, or referred onwards to a specialist clinic for further treatment. One notable aspect of the PCC is that it has had access to information technology since its inception.

From: The Primary Care Service, Moorfields Eye Hospital, City Road, London EC1V 2PD, UK.

Correspondence to: Mr Charles Claoué, MD, FRCS, Consultant Ophthalmic Surgeon, North East London Eye Partnership, Whipps Cross Hospital, Whipps Cross Road, London E11 1NR, UK.
At the end of all consultations the ophthalmologist enters data on diagnosis, investigations, management and outcome. This is used to generate a letter to the referring doctor, but also provides data useful for planning the service.

It is an explicit aim of the PCC that no patient should re-attend except as a re-referral for a new problem - hence the alternative name of a 'Dedicated New Patient Clinic'. Patients seen in the PCC are referred by general practitioners and optometrists. Patients who have been seen by other ophthalmologists who wish to transfer their care (tertiary referrals) and patients seeking second opinions are diverted directly to specialist clinics.

Since 1991, all new patients have been seen in the PCC. However, in April 1993 an outreach clinic was opened approximately 4 miles east of the main hospital in an inner city area of relative deprivation but high population density. This clinic is run in an identical fashion to the PCC at the main hospital. Patients directed to this clinic were those living locally and in an eastern corridor beyond the immediate vicinity.

\section{PATIENTS AND METHODS}

The data base created by the direct entry of data by the clinician at the time of consultation was analysed to produce the following data: total number of attendances, total number of patients, age, gender, diagnosis and outcome. Outcomes could be discharge, immediate admission, or onward referral to one of the specialist clinics (external disease, glaucoma, medical retina, adnexal, cataract, strabismus and paediatric, neuro-ophthalmology, or surgical retina). 
Wherever possible, similar figures were produced for both the principal PCC and the outreach PCC. Statistical analysis was by chi-squared test, $t$-test and $95 \%$ confidence intervals as appropriate.

\section{RESULTS}

A total of 64417 attendances were analysed, representing 56409 patients. Of the 64417 attendances, 8008 represented re-attendances $(12.4 \%)$. In the majority of cases, re-attendances represented a new problem, or exacerbation of an existing problem for which the patient had been discharged (such as early cataract).

Overall, $43.5 \%$ of patients were male and $56.5 \%$ female. In 82 cases $(0.014 \%)$ no gender was recorded. Overall, $8.8 \%$ of patients were aged $0-15$ years, $63.7 \%$ between 16 and 69 years, and $27.5 \% 70$ years or older. There was a higher proportion of patients under 16 years of age seen at the outreach clinic $(11.0 \%)$ than at the main hospital $(8.6 \%)$ $(p<0.001)$. This difference was highly statistically significant both for girls $(p=0.009)$ and for boys $(p<0.001)$. In contrast, more patients in the 16-69 years age group were seen at the main hospital than in the outreach clinic $(p<0.001)$. There was no statistically significant difference for patients over 70 years. There was a higher proportion of female patients aged 70 years or over $(30.7 \%)$ than male patients $(23 \% ; p<0.001)$. Interestingly, there was a higher proportion of male patients $(9.9 \%)$ under 16 years than female patients $(7.8 \% ; p<0.001)$.

Table I. Comparison of the 12 commonest diagnoses of patients attending the Primary Care Clinic in 1993 with those attending in 1991

\begin{tabular}{|c|c|c|c|c|c|}
\hline Diagnosis & \multicolumn{2}{|c|}{1991} & \multicolumn{2}{|c|}{1993} & Probability \\
\hline $\begin{array}{l}\text { Cataract and early } \\
\text { lens opacities }\end{array}$ & 3860 & $25.3 \%$ & 4791 & $27.8 \%$ & $p=0.000001$ \\
\hline Blepharitis & 1394 & $9.1 \%$ & 1839 & $10.6 \%$ & $p=0.000001$ \\
\hline Refractive error & 685 & $4.5 \%$ & 1395 & $8.1 \%$ & $p=0.0000001$ \\
\hline $\begin{array}{l}\text { Age-related macular } \\
\text { degeneration }\end{array}$ & 921 & $6.0 \%$ & 1160 & $6.7 \%$ & $p=0.014$ \\
\hline Chalazion & 618 & $4.1 \%$ & 801 & $4.6 \%$ & $p=0.011$ \\
\hline $\begin{array}{l}\text { No ophthalmic } \\
\text { abnormality } \\
\text { detected }\end{array}$ & 815 & $5.3 \%$ & 777 & $4.5 \%$ & $p=0.0004$ \\
\hline $\begin{array}{l}\text { Negative glaucoma } \\
\text { screening }\end{array}$ & 524 & $3.5 \%$ & 689 & $4.0 \%$ & $p=0.009$ \\
\hline Strabismus & 566 & $3.7 \%$ & 669 & $3.9 \%$ & $p=0.46 \mathrm{NS}$ \\
\hline Glaucoma & 646 & $4.2 \%$ & 651 & $3.8 \%$ & $p=0.03$ \\
\hline Amblyopia & & - & 514 & $3.0 \%$ & - \\
\hline $\begin{array}{l}\text { Posterior vitreous } \\
\text { detachment }\end{array}$ & 416 & $2.7 \%$ & 458 & $2.6 \%$ & $p=0.20 \mathrm{NS}$ \\
\hline Dry eye & 421 & $2.8 \%$ & 418 & $2.4 \%$ & $p=0.031$ \\
\hline $\begin{array}{r}\text { Total no. of } \\
\text { diagnoses }\end{array}$ & & 065 & & 76 & \\
\hline $\begin{array}{l}\text { Total no. of } \\
\text { attendances }\end{array}$ & & 240 & & 286 & \\
\hline
\end{tabular}

Figures given are number of times diagnoses were entered. Percentages represent proportion of all patients. Diagnostic coding of amblyopia was not available for the whole of 1991.
Common diagnoses included amblyopia, agerelated macular degeneration, blepharitis, cataract, chalazion, conjunctivitis, diabetic retinopathy, dry eyes, early lens opacities, glaucoma-related diagnoses, no ophthalmic abnormality detected, presbyopia, posterior vitreous detachment, refractive error, strabismus and uveitis. Since one patient could have multiple diagnoses, the total number of diagnoses exceeds the number of patients. Overall, the ratio is 1.3 diagnoses per attendance. In 1993, from 17286 attendances the commonest diagnoses were: (1) cataract (2636), (2) early lens opacities (2155), (3) blepharitis (1839), (4) refractive error (1395), (5) age-related macular degeneration (1160), (6) chalazion (801), (7) no ophthalmic abnormality detected (777), (8) negative glaucoma screening (689), (9) strabismus (669), (10) positive glaucoma screening (651), (11) amblyopia (514), (12) posterior vitreous detachment (458) and (13) dry eye (418).

Comparison of the 12 commonest diagnoses in 1993 and 1991 is shown in Table I. In 1991 there was a mean of 1.18 diagnoses per attendance, whereas in 1993 this had increased to $1.31 \quad(p<0.001)$. A comparison was also made of those patients attending the main PCC and the outreach clinic. The analysis was for the period 1 April 1993 to 31 March 1994. Details are shown in Table II. As can be expected from the large sample size, $95 \%$ confidence intervals for the observed differences in proportion are of the order of $0.4 \%$ throughout.

Table II. Analysis of 1 year of the 12 commonest diagnoses to compare the main hospital-based primary care clinic with an identical clinic functioning in the community as an outreach clinic

\begin{tabular}{|c|c|c|c|c|c|}
\hline Diagnosis & $\begin{array}{r}\text { Prima } \\
\mathrm{Cl}\end{array}$ & $\begin{array}{l}\text { ry Care } \\
\text { linic }\end{array}$ & $\begin{array}{r}\text { Out } \\
\text { PC }\end{array}$ & $\begin{array}{l}\text { reach } \\
\text { CC }\end{array}$ & Probability \\
\hline $\begin{array}{l}\text { Cataract and early } \\
\text { lens opacities }\end{array}$ & 4274 & $26.6 \%$ & 1979 & $35.3 \%$ & $p=0.0000001$ \\
\hline Blepharitis & 1710 & $10.6 \%$ & 787 & $14.0 \%$ & $p=0.0000001$ \\
\hline Refractive error & 1330 & $8.3 \%$ & 553 & $9.9 \%$ & $p=0.0003$ \\
\hline $\begin{array}{c}\text { Age-related macular } \\
\text { degeneration }\end{array}$ & 1012 & $6.3 \%$ & 290 & $5.2 \%$ & $p=0.0024$ \\
\hline Chalazion & 766 & $4.8 \%$ & 264 & $4.7 \%$ & $p=0.87 \mathrm{NS}$ \\
\hline $\begin{array}{l}\text { No ophthalmic } \\
\text { abnormality } \\
\text { detected }\end{array}$ & 757 & $4.7 \%$ & 220 & $3.9 \%$ & $p=0.015$ \\
\hline $\begin{array}{l}\text { Negative glaucoma } \\
\text { screening }\end{array}$ & 619 & $3.8 \%$ & 180 & $3.2 \%$ & $p=0.029$ \\
\hline Strabismus & 575 & $3.6 \%$ & 248 & $4.4 \%$ & $p=0.0042$ \\
\hline Glaucoma & 560 & $3.5 \%$ & 336 & $6.0 \%$ & $p=0.0000001$ \\
\hline Amblyopia & 506 & $3.1 \%$ & 233 & $4.2 \%$ & $p=0.00033$ \\
\hline $\begin{array}{l}\text { Posterior vitreous } \\
\text { detachment }\end{array}$ & 392 & $2.4 \%$ & 172 & $3.1 \%$ & $p=0.011$ \\
\hline Dry eye & 388 & $2.4 \%$ & 107 & $1.9 \%$ & $p=0.030$ \\
\hline $\begin{array}{r}\text { Total no. of } \\
\text { diagnoses }\end{array}$ & \multicolumn{2}{|c|}{21298} & \multicolumn{2}{|c|}{8376} & \\
\hline $\begin{array}{l}\text { Total no. of } \\
\text { attendances }\end{array}$ & \multicolumn{2}{|c|}{16092} & \multicolumn{2}{|c|}{5608} & \\
\hline
\end{tabular}

Figures given are number of times diagnoses were entered. Percentages represent proportion of all patients.

NS, not statistically significant. 

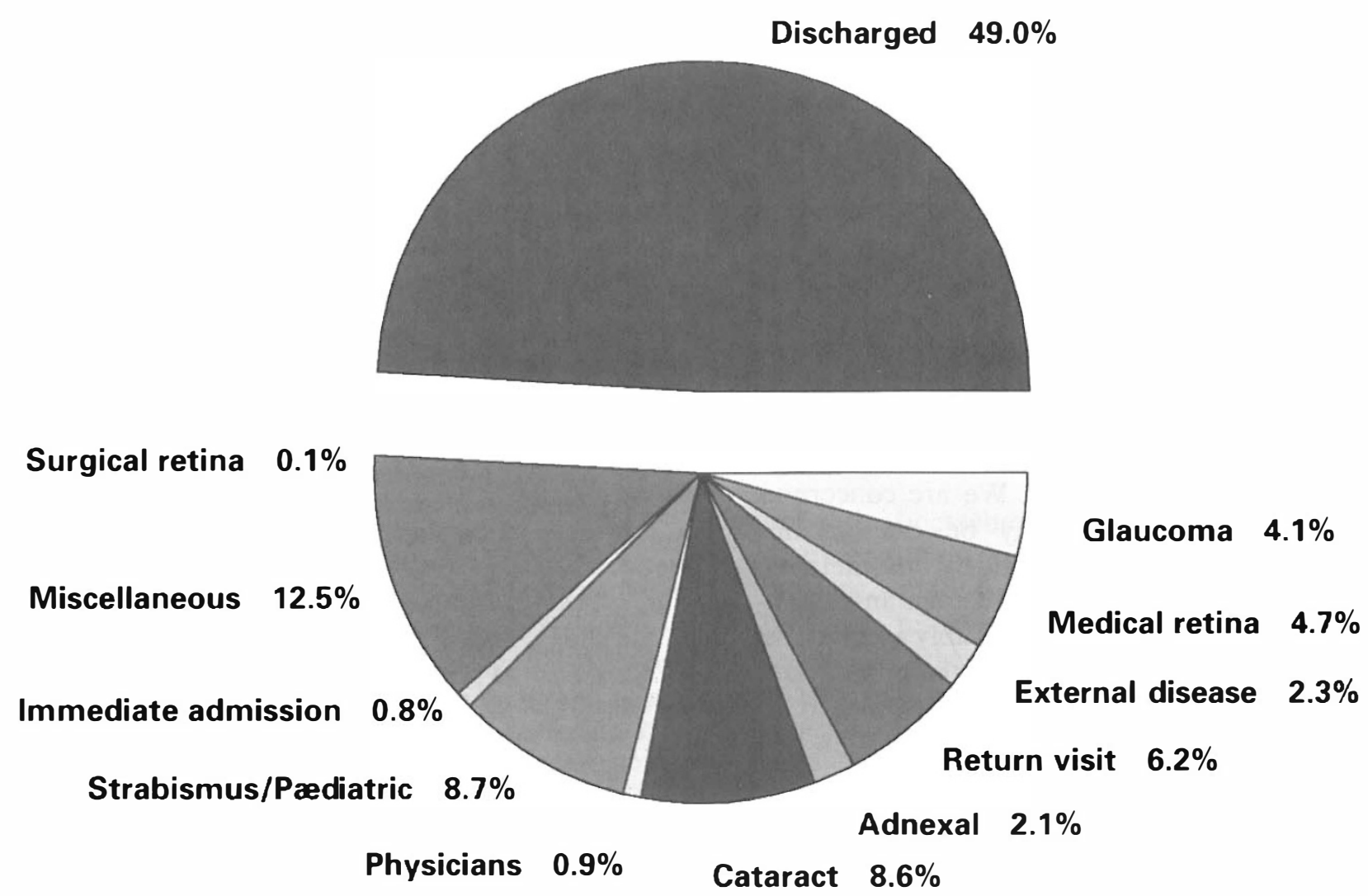

Fig. 1. Outcome of 64417 patient visits.

The outcome of the clinic attendance was also analysed for the 64417 attendances. The commonest outcome by far was for the patient to be discharged (49\%). Other outcomes are shown in Fig. 1.

\section{DISCUSSION}

There is a paucity of information about the epidemiology of ophthalmic disease in most populations; indeed the true incidence is rarely known. ${ }^{1}$ Many attempts to quantify the real prevalence of eye disease have involved relatively small populations and have concentrated on establishing the prevalence of undiagnosed eye disease in the community. ${ }^{1,2}$ Whilst this gives useful insight into maximum potential demand, those involved with the planning of the delivery of ophthalmic services are interested in real demand, and in order to plan services require information on the relative frequencies of acute and chronic conditions and the proportion of new patients likely to require surgery or long-term medical care.

Other surveys have concentrated mainly on ophthalmic accident and emergency clinics, ${ }^{3-6}$ which do not reflect the non-urgent nature of many ophthalmic problems. Dart, ${ }^{7}$ in 1986 , reported on patients seen in a community health centre, but it is not known how this relatively small study relates to referrals to hospital-based clinics, as much ophthal- mic disease is managed in the community. ${ }^{8}$ Surveys have also sought asymptomatic disease in general medical clinic populations. ${ }^{9,10}$

To our knowledge, there is only a single publication regarding a similar clinic. ${ }^{11}$ It is noteworthy that the frequency with which patients are discharged in our model is very significantly higher $(p<0.0000001)$ at $49 \%$ than in the Warrington model $(41 \%) .{ }^{11}$ Unfortunately, this paper does not provide information on diagnoses.

The siting of specialist clinics in an outreach setting is appealing, but the appropriateness of this has been questioned. $^{12,13}$ In ophthalmology, the need for complex equipment such as computerised visual field anlaysers, and Professions Allied to Medicine such as orthoptists, restricts most outreach sites due to space restrictions. It is interesting to see that when we sited the PCC in an outreach setting, the patients seen were of a different age and had different relative incidences of the same common diagnoses compared with those at the main hospital. Whilst we have no data to confirm our belief that the 'average socio-economic status' of patients at the two sites is different, it is recognised that this factor can influence the prevalence of eye disease. ${ }^{14}$

Some of our results are not surprising; for example, that almost $30 \%$ of patients were aged 70 years or older. Others, such as the relative increase in 
numbers of young patients in an outreach setting, have not previously been documented, and probably reflect highly localised demographics. Similarly, it is perhaps surprising to find an increased number of young male patients (under 16 years) with nonurgent ophthalmic problems, since any traumatic pathology would presumably have presented to the ophthalmic casualty department rather than the PCC.

The commonest diagnoses are also relatively predictable, but it is surprising to see that some diagnoses have either increased (refractive error) or decreased (glaucoma, no abnormality detected) in frequency over a 2 year period. We are concerned that some of this change may be due to the introduction of fees for sight-testing by optometrists.

The increased prevalence of glaucoma and cataract in our outreach clinic is also probably a reflection of the local socio-economic status of the population, but it was interesting to see that there appeared to be a highly statistically significant difference in the frequency of blepharitis and dry eye between the two populations, as this had not been expected.

In summary, we have reported the epidemiological parameters and commonest diagnoses for 64417 patient-attendances by 56409 patients to a dedicated ophthalmic new patient clinic. Forty-three point five per cent were male and $56.5 \%$ female. Nine per cent of patients were under 16 years of age while $27.5 \%$ were over 70 years. Comparison of patients attending an outreach new patient clinic with that at the main hospital showed that a higher proportion of patients under 16 years were seen at the outreach clinic $(p<0.001)$, whereas the main clinic saw a higher proportion of patients in the 16-69 year age group $(p<0.001)$. Over a 2 year period there appeared to be an increase in the number of patients with refractive error presenting and a reduction in those with glaucoma.
The authors would like to thank all their colleagues who have worked in the Primary Care Service.

Key words: Eye disease, Diagnosis, Epidemiology.

\section{REFERENCES}

1. Kini MM, Leibowitz HM, Coltyon T, Nickerson RJ, Ganley J, Dawber TR. Prevalence of senile cataract, diabetic retinopathy, senile macular degeneration and open angle glaucoma in the Framingham eye study. Am J Ophthalmol 1978;85:28-34.

2. Tielsch JM, Sommer A, Witt K, Katz J, Royall RM. Blindness and visual impairment in an American urban population. Arch Ophthalmol 1990;108:286-90.

3. Jones NP, Hayward JM, Khaw PT, Claoué CMP, Elkington AR. Function of an ophthalmic 'accident and emergency' department: results of a six month survey. BMJ 1986;292:188-90.

4. Wong D, Brazier DJ. Primary ophthalmic care: why did patients choose to come to the accident and emergency? Trans Ophthalmol Soc UK 1986;105:510.

5. Chiapella AP, Rosenthal AR. One year in an eye casualty clinic. Br J Ophthalmol 1985;69:865-70.

6 . Vernon SA. Analysis of all new cases seen in a busy regional ophthalmic casualty department during a 24 week period. JR Soc Med 1983;76:279-82.

7. Dart JKG. Eye disease at a community health centre. BMJ 1986;293:1470-80.

8. McDonnell PJ. How do general practitioners manage eye disease in the community? Br J Ophthalmol 1988; 72:733-6.

9. Wang F, Ford D, Tielsch JM, Quigley HA, Whelton PK. Undetected eye disease in a primary care clinic population. Arch Intern Med 1994;154:1821-8.

10. Strahlman E, Ford D, Whelton P, Sommer A. Vision screening in a primary care setting. Arch Intern Med 1990;150:2159-64.

11. Peckar CO, Wishart MS, Jalili IK, Mathew $P$. Ophthalmic primary care: the Warrington model. Eur J Implant Ref Surg 6:2-5.

12. Harris A. Specialist outreach clinics. BMJ 1994;308: 1053.

13. Bailey J, Wilkin D, Black ME. Specialist outreach clinics in general practice. BMJ 1994;308:1083-6.

14. Tielsch JM, Sommer A, Katz J, Quigley H, Ezrine S. Socioeconomic status and visual impairment among urban Americans. Arch Ophthalmol 1991;109:637-41. 